\title{
After the Prestige: A Postmodern Analysis of Penn and Teller
}

\author{
Elizabeth L. Miller \& Joseph P. Zompetti
}

Liz Miller is a third year PhD student in the department of communication studies at the University of Kansas. She received her Masters at Illinois State University and her Bachelor's at Miami University. Her main research interests lie at the nexus between the rhetoric of science and the rhetoric of Islam.

Joseph P. Zompetti (Ph.D., Wayne State) is Professor in the School of Communication at Illinois State University. His research interests include the rhetoric of magic, political communication, rhetorical theory and argumentation. He has published extensively in journals such as the Western Journal of Communication, Culture Theory \& Critique, and Argumentation.

\begin{abstract}
By mocking the magic community and revealing the secret behind some of their tricks, Penn and Teller perform a kind of parodic and post-modern "anti-magic." Penn and Teller display an artful use of rhetoric; in exposing the secrets and shortcomings of conjuring, they are revolutionizing the way people think about both the art of magic and the magic community. Individuals such as Penn and Teller may use parody to subvert the hegemonic interpretations. However, we also know that it is difficult to bring down a system while operating within that system. Thus, this article explores the way Penn and Teller are challenging the metanarrative of the magic community, using several of the duo's more popular illusions as examples for analysis. Ultimately, this paper should help us gain a better understanding of the way parody can be used to challenge hegemonic conceptions, and the limitations of this type of rhetorical approach.
\end{abstract}

\section{KEYWORDS}

Magic, magical community, parody, hegemony 
Every great magic trick consists of three acts. The first act is called "The Pledge"; the magician shows you something ordinary, but of course... it probably isn't. The second act is called "The Turn"; the magician makes his ordinary some thing do something extraordinary. Now if you're looking for the secret... you won't find it, that's why there's a third act called, "The Prestige"; this is the part with the twists and turns, where lives hang in the balance, and you see something shocking you've never seen before.

-Cutter, The Prestige (Nolan \& Nolan, 2006)

\section{THE PLEDGE}

For those individuals who are tired of the same old top hats and top-billed magic acts, Penn and Teller provide a refreshing alternative. The two call their longrunning Las Vegas act "The Magic Show for People Who Hate Magic Shows" (Teller in Alesia, 1994, p. 3). Whether or not magic-hating audience members really do prefer this act is unclear, but there is an excellent argument to be made that Penn and Teller perform a kind of post-modern "anti-magic." Garman (2003) asserts that Penn and Teller's performances are a "commentary on the performers, the audience, the world and magic itself" (para. 6). And Penn and Teller do not just poke fun at other magic acts. The devious duo actually reveal the secrets behind certain magic tricks as a part of their routine (Andrew, 2010), prompting Curtis (2006) to dub their act a "comic deconstruction of the magic show" (para. 2). Similarly to Tommy Cooper's blending of comedy and magic in a deconstructed form (Bleach, 2014), Penn and Teller have two speeds: They either aim to amuse their audience with ironic hilarity or to horrify their audience with excessive gore. Teller has been quoted as saying, "We like it to be funny or make the little hairs stand up on the back of our collective neck" (in Maue, 2001, para. 17). No matter which tack they take, P\&T are always entertaining. In keeping the audiences' rapt attention, Penn and Teller display an artful use of rhetoric; in exposing the secrets and shortcomings of modern conjuring, they are revolutionizing the way millions of people think about both the art of magic and the magic community.

\section{ILLUSIONISTS, INTELLECTUALS, KINGS OF IRONY: PENN AND TELLER}

Penn Jillette and Teller (legally his full name) are some of the most distinct characters in show business (Krewen, 1997). Penn is a "hyperkinetic impresario" he is over six and a half feet tall, with a booming voice and an overbearing sense of humor (Lehrer, 2009). Teller serves as Penn's phlegmatic foil-he is a foot shorter, never speaks onstage, and moves with an "eerie grace" (Lehrer, 2009). Penn and Teller do not cloak themselves in traditional magician's garb-they wear crisp matching business suits, keeping the act modern (Sorenson, 1994). Generally, Penn is the one in charge-he dominates Teller with hilarious running commentary, and rigs and runs the dangerous illusions. Teller is simultaneously the straight man and the silent victim. If an illusion calls for someone to be set on fire or dangled over spikes, 
the unlucky target is usually Teller (Brown, 1987; Krewen, 1997; Sorenson, 1994). The two have performed together since the mid-1970s, when Teller left his job as a high school Latin teacher to join Penn and a mutual friend in an early incarnation of the act (Alesia, 1994). Eventually, Penn and Teller split off to perform together-and if their success is any indication, the two make a fantastic team.

In the 1980s, Penn and Teller became popular by revealing the secrets of well-known magic tricks (The Guardian, 2011). Penn and Teller's website lists their impressive accomplishments since that time. The two have performed on Broadway, launched several Emmy-winning television series, and won the "Las Vegas Magicians of the Year" award six times, including in 2011 (Jillette \& Teller, n.d.). According to their biography, Penn and Teller's act is "one of the longest running and most-beloved shows in Las Vegas history," considering that they have performed there for over ten years and outsold almost every other magician on the Strip (para. 3). In 2009, Forbes listed Penn and Teller as $96^{\text {th }}$ on their "Celebrity 100" list, valuing them at \$20 million ("The Celebrity 100," 2009). Clearly, Penn and Teller are popular performers, and thus have had the opportunity to spread their message to millions of people. And their message is simple: Be skeptical about everything (especially "magic"). Lehrer (2009) says that partly because of Penn and Teller's antics, contemporary audiences are "both hungrier for deception and savvier about its practice" (para. 18). To understand how Penn and Teller have reshaped the mind of the average spectator, we can examine the duo's use of postmodernity to overthrow the metanarrative of the magic community.

\section{THE METHOD (OF ANALYSIS)}

Jameson (1988) asserts that postmodern scholars are obsessed with "low" culture: "advertising and motels... the Las Vegas strip... the late show and Grade-B Hollywood film" (p. 14). Despite Robert-Houdin's attempt to change its image (Mangan, 2007), modern magic is considered low culture, and is thus appropriately examined through the lens of postmodernism. It may seem strange that postmodernism is part of the pledge, since the pledge is supposed to consist of ordinary elements-and postmodernism critiques the ordinary. Postmodernism inverts everything we think we know about reality, turning up into down, black into white, and scientific rationalism into metaphysical relativism. Lyotard (1979/1984), defined postmodernism as an "incredulity toward metanarratives" (p. xxiv). Bevel (2004) explains that metanarratives are all-encompassing schemes of thought that establish rules and maintain order in a culture. They are based on the notion that objective truth exists, and each one allows for a single set of "criteria for judgment" (p. 16). Reliance on metanarratives is a defining characteristic of modernity, and postmodern scholars attempt to demonstrate how unreliable metanarratives are (Best \& Kellner, 1991). However, despite the fact that postmodernism is used to critique the ordinary, as an unapplied ideology it is nothing that cannot be grasped. 
Postmodernism has nothing up its sleeves. It is merely a tool in the toolbox, a method for dismantling, examining, and ultimately overturning hegemonic power.

The concept of power is central to postmodernism. Bevel (2004) explains the distinction between metanarratives and little narratives. Little narratives are the individual stories that are told and retold by ordinary people; they "tell the story of a culture" (p. 15). Metanarratives are sociocultural paradigms that subsume all of the little narratives, privileging a single viewpoint while "marginalizing, regimenting, or overtly oppressing the voices of divergence" (Thompson, 1992, p. 325). Lyotard $(1979 / 1984)$ claimed that the foremost metanarrative in our society is that of scientific rationality. However, a metanarrative might be based in religion, or politics; it might exalt feminist theory; it might simply constitute a unifying social message, like the "hard work leads to success" metanarrative central to the American Dream. GilbertWalsh (2007) asserts that when a metanarrative has taken hold of a culture, all of the little narratives must ultimately be justified based on that metanarrative. Those who wish to speak in opposition of a metanarrative may have trouble sharing their thoughts, because powerful individuals will do almost anything to defend the metanarratives that provide them with some level of authority (Bevel, 2004).

Despite the power of metanarratives, Lyotard (1979/1984) claims that contemporary societies are eschewing them in favor of postmodern sensibilities; basically, "the grand narrative has lost its credibility" (p. 37). In his view, the best way to overturn metanarratives is through dissent, through questioning the grand doctrines that preside unnoticed over our everyday lives (Best \& Kellner, 1991). Parodic texts often play this role. Kreuz and Roberts (1993) define parody as "imitation, intended to ridicule or criticize" (p. 102), and Goetsch (1980) reminds us that not only is it necessary for parody to distort another text, it must do so in a comic manner, simultaneously mocking and critiquing its target in a way that makes an audience laugh. When used successfully, parody can be a powerful force for cultural change (Gray, 2005). Parody inverts the social order, debasing "elevated" subjects (metanarratives) and exalting "lowly" subjects (marginalized narratives) (Kreuz \& Roberts, 1993). Part of the reason parody is so effective in questioning metanarratives is because it uses humor as a rhetorical vehicle. Because of its nonserious nature, humor is often underrated as a persuasive force; however, it can be profoundly useful to a savvy rhetor. Meyer (2000) explains that humor can be used to ridicule others while at the same time fostering identification with and ultimately bringing together the group being addressed. Humor can be passed off as nonthreatening but still communicate a message, and thus gives otherwise powerless individuals "an insulated means of argument to challenge the dominant view of the social order" (Smith, 1993, p. 51). By reworking and mocking the source material, a text can constitute a successful parody and thus serve as a postmodern critique of the metanarrative off of which it feeds. 
A core component of parodic texts is their intertextual nature. Intertextuality can mean one of two things: (1) an audience is decoding a text by calling to mind relevant aspects of all the texts they have encountered previously, or (2) an author is deliberately referencing another text, hoping that the audience will notice and understand the reference (Ott \& Walter, 2000). Since parody is about reshaping a text or a genre to make a point, the second definition is particularly relevant to our discussion. Gray (2005) calls intertextuality the "engine of parody" (p. 226), and Hutcheon (1989) asserts that postmodern texts are usually characterized by "overtly parodic intertextuality" (p. 3). Intertextual references must be made with care. First of all, a rhetor must accurately gauge the sophistication level of his or her audience-if an intertextual reference is too clever or too obscure, it might go unnoticed, rendering it useless. Second, a rhetor must display in-depth knowledge about the text they are mocking - if parody is too far removed from the original, it will come across as a shallow and ineffective critique (Kreuz \& Roberts, 1993). Essentially, by intertextually referencing other texts or genres, a text can constitute a successful parody and thus serve as a postmodern critique of the metanarrative off of which it feeds.

\section{THE METANARRATIVE OF THE MAGIC COMMUNITY}

Although no two magic acts are exactly the same, Lamont and Wiseman (1999/2010) claim that all tricks have the same basic structure: The magician "employs a method (how the trick works) to produce an effect (what the spectator perceives)" (p.1). In order for a trick to be successful, the spectator must "experience the effect while being unaware of the method" (p. 1). The compulsory disconnect between method and effect necessitates careful secrecy on the part of the magician (Sharpe, 2003). There are two rules firmly embedded within the magic community to keep secrets from being revealed. First, conjurors should not disclose in advance what the effect will be. If they do, the spectator might be able to follow the performance closely enough that he or she figures out the method (Fitzkee, 1945/2009). Second, conjurors should not repeat a trick, and not just because "a twice-shown illusion falls as flat as a twice-told joke" (Nelms, 1969/2000, p. 228). If a magician does a trick twice, spectators might follow more closely the second time and, just as before, figure out the method. Several societies have popped up to protect the tricks of the trade. For example, the motto of the Magic Circle is Indocilis Privata Loqui, which translates to "not apt to disclose secrets" (Soteriou, 2010).

Some authors dismiss the importance of secrecy in the magic community. Lamont and Wiseman (1999/2010) remind us that magical secrets are frequently revealed on television and in magic shops. Despite all this secret telling, the magic community survives. Fitzkee (1943/2009) claims that the real secrets of magic have to do with dominating the mind of the spectator and cannot be performed by a layperson who only knows the technical aspects of a trick. He goes on to state, "Shell bottles do not constitute any part of the true secrets of magic. Neither do folding bird cages... Nor 
pulled threads. Nor folding flowers" (p. 13). It is not the mechanical aspects of a trick that make it great. The same effect can be accomplished with an almost infinite number of methods, and the final outcome will essentially be the same in the eyes of the audience. What makes a magic trick great, says Fitzkee (1945/2009), is performance.

Robert-Houdin famously stated that magicians are actually actors "playing the part of a magician" (1877, p. 43). It is common for magicians to employ incantations and rituals to make their illusions seem like true witchcraft (Gloye, 1978). More than just executing the proper rituals, many scholars argue that magicians should frame themselves as if they can actually perform magic, so that role and person become "intertwined" (Nardi, 1984). Performance magic blurs the line between what is and is not possible, simultaneously exciting and disturbing the audience as they try to cling to what they know about the laws of nature (Mangan, 2007). Now, obviously, modern audiences are not likely to believe in "real" magic. Even back in 1945, Fitzkee (1945/2009) warned that audiences will not buy supernatural explanations for supposedly magic phenomena. However, even though people ultimately recognize the falsity of performance magic, this does not mean they cannot be dazzled. Hass (2007) says that after a well-performed illusion, "there is this incredible moment when the world we know collapses, when our vision condenses, when our chest bursts with feeling, and our jaw hangs open" (p. 153). Good performance magic sweeps up an audience and convinces them to suspend disbelief, if only for an instant.

Sharpe (2003) makes the argument that performance magic is supposed to enchant the audience; that a magician's ultimate goal is "not to deceive people but to encourage them to approach life and cosmos in a state of wonder" (p. 83). According to this line of thinking, magic is not just supposed to entertain us; it is supposed to remind us that there are mysteries of the cosmos that cannot and should not be solved (Burger \& Neale, 1995/2009). Unfortunately, people have a natural drive to figure out secrets; they "reflexively seek to find a way to put it all back in place, to analyze and explain the impossible" (Hass, 2007, p. 155). The goal of the magician should be to produce more extraordinary moments; therefore, he or she should draw attention away from the mechanics of a trick and persuade the audience to take in the wonder of the occurrence.

Despite the profundity of this viewpoint, modern magicians often frame their illusions as problems to be solved, challenging the audience to figure out the method if they can (Mangan, 2007). Loshin (2007) says that when a person does not know the secret between the Pendragons' split-second illusion, Metamorphosis, it is a "thing of beauty;" however, if that person does know the method, it becomes little more "impressive technical feat, or at best a physical puzzle" (p. 15-16). Burger and Neale (1995/2009) agree, asserting that an audience member who is always trying to 
"solve" magic tricks is not fully enjoying the experience-in fact, the authors argue, that person is not experiencing magic at all. Magicians must ask themselves if they are, in any way, daring the audience to uncover the secret behind the trick, and if so, alter their behavior, because this attitude can detract from the magic of the experience (Burger, 2009a). Challenging people to figure out the method has the further consequence of making the audience members feel inferior to the magician (Nelms, 1969/2000). Gloye (1978) says that adopting the role of challenger makes a magician seem unforthcoming, egotistical, and ultimately unlikable to the audience.

Unfortunately, magicians often underestimate the intelligence of their audience, and thus perform tricks that even a child could see through (Fitzkee, 1945/2009). The audience might even be insulted that the magician thought they were so stupid that they would not see through such poor pretense. A careful balance must be struck when performing illusions, because spectators are "torn between the enjoyment of belief and the resentment of being fooled" (Neale, 2009a, p. 43). This situation is further complicated when magicians fail to frame themselves as sympathetic characters. Renowned magician Eugene Burger (2009b) says that during his travels, he has met many kind and "delightful" human beings who, when they begin to perform magic for an audience, become much less likeable, because of their insistence on turning the performance into a competition between themselves and the audience.

One way for a magician to retain likeability is to use comedy. Humor helps ease the tension created when an audience member feels threatened or challenged by an arrogant performer (Nardi, 1984). Since the main goal of comedy magic is to entertain, a magician can use humor to "go against the norm" which adds uniqueness and likeability (Roper, 1986, p. 23). There are two main ways that magicians use humor in performance. First, magicians can capitalize on the humor found in the "inherent incongruity of the effects" (Sharpe, 2003, p. 310). If a performer places a poorly-dressed man into a cabinet and a evening-gown-wearing woman hops out in his place, the audience may be startled into laughing at the incongruity of the situation. Second, Fitzkee (1943/2009) says that audiences "find comedy in the difficulties, shortcomings, and inconsistencies of other people, creatures, and things" (pp. 102-103). In order to avoid the trap of superiority a magician can act like an incompetent bumbler, botching tricks and tripping over his or her own feet, so that the audience actually gets to find humor in the fact that they are the superior half of the relationship (Sharpe, 2003).

An additional benefit of comedy is that it keeps grave themes from darkening an entire show. The magic community seems to be full of thanatophiles: Magicians are constantly sawing women in half, stabbing them with swords, and submerging them in water tanks. One of the most famous magicians of all time, Houdini, had a particularly "melodramatic imagination"; his acts of escapology were terrifying to 
those who believed he was truly in danger. The documentary Grand Illusions says that performance magic is often a "flirtation with death." (Ness, 2002). However, Burger and Neale (1995/2009) explain that magicians frequently use comedy to "challenge the power of death and suffering" (p. 211). Magic is about more than just death-it is also about resurrection (Mangan, 2007). A magic trick becomes humorous in the instant that we overcome anxiety about our own mortality - this indicates that tragedy has given way to comedy and "destruction itself has been destroyed" (Neale, 2009b, p. 95). Ultimately, we use magic to control our fear of the great unknown.

The metanarrative of magic is tied up with the notion of control. Mangan (2007) asserts that at its heart, "conjuring is all about power-of one sort or another" (p. 9). All the secrecy of the magic community is basically about controlling information, and, theoretically, the end result of magical powers is control of the natural world (Loshin, 2007). Sankey (2003) speaks of a dialectic between control and mystery that is inherent in all performance magic; he states, "puzzles reek of a desire to control the experience, while mysteries only bloom in moments where the performer relinquishes just the right amount of control" (p. 127). Mangan (2007) argues that conjuring is a postmodern activity, in that it challenges the metanarrative of scientific rationality by allowing people to experience wonder and appreciate metaphysics and unsolved mysteries. In doing so, the magic community has actually created its own metanarrative, with an emphasis on wonderment and spirituality. Historically, social power was held by the religious establishment, whose members often used magic to reinforce their authority (Mangan, 2007). Priests would utilize all manner of technologically-based illusions: "Milk and wine flowed from altars, sacred flames lit spontaneously...and water changed into wine" (pp. 7-8). These illusions allowed them to maintain control over the masses who did not understand how to operate such sophisticated technology and thus could not see through the deception of the religious establishment.

Over time, "supernatural magic" has been replaced by "secular magic" (Loshin, 2007, p. 4). But there are vestiges of the supernatural clinging to modern magic. Pseudo-psychics still try to convince the masses that they can truly read minds (Lamont \& Wiseman, 1999/2010), and modern-day miracle workers/televangelists give a bad name to religious leaders who lead their followers without deception. But some members of the magic community are uncomfortable with perpetuating chicanery, including Penn and Teller. In some ways, Penn and Teller pattern themselves after Houdini (an idol of both men), who spent the later part of his career debunking psychics and spiritualists ( $\mathrm{Tu}, 1997)$. A few years ago, the duo starred in a television series called "Bullshit!" in which they took on and debunked anything they found fraudulent about popular culture ("A twisted history," n.d.)-alien abductions, organic food myths, religion, etc. Magic does not just have to be used to 
deceive an audience. It can also be used to remind people that illusions are just illusions, and that not everything is as it appears to be (Sharpe, 2003).

\section{THE TURN}

\section{THE SIGNATURE STYLE OF PENN AND TELLER: “LOOKS SIMPLE” AND THE CUPS \& BALLS}

"Looks Simple" and the cups \& balls bit are among the most well-known illusions of Penn and Teller. In "Looks Simple," Penn plays the bass guitar and narrates a slight of hand routine performed by Teller, in which he manipulates a cigarette, making it appear, disappear, and reappear-lit, unlit, and then lit again. After Teller successfully completes the first half of the bit, he turns around so that the audience can see his other side-and thus all of the secret techniques used in the routine. Penn seizes this opportunity to educate the audience about the seven basic principles of legerdemain: palming, ditching, stealing, loading, simulation, misdirection, switching (WastyinTahiti, 2009). This trick reveals several things about the style of the duo. First, it provides an accurate character template: Penn does all the talking; however, although Teller remains silent, his nimble fingers and sly facial expressions tell the audience plenty about his onstage persona (Brown, 1987). The routine also illustrates Penn and Teller's unconventional approach to deception. In the beginning, it seems as though Teller is performing a normal behavior-smoking a cigarette. It soon becomes apparent that he is lying to his audience without the use of words. The idea of wordless deception fascinates Teller, since "lying is usually relegated to speaking falsely" (in Cohen, 1994, p. H1). However, even though the routine involves deception at first, it also involves a reveal-Penn tells and Teller shows exactly how the trick works, simultaneously helping the audience to understand the ways that they may have been duped by sleight of hand in the past.

Penn and Teller enjoy breaking the rules of magic, and nowhere is this better illustrated than in their groundbreaking take on the cups \& balls. In this routine, Penn and Teller execute a dual performance of one of the oldest tricks in magicthey use three cups and a variety of balls, making them appear, disappear, and reappear in a variety of combinations and impressively rapid sleights. After performing the trick once, Penn declares that this was the "standard version," and that they are now going to perform the "Penn and Teller version" of the same trickand this time, they are going to use clear cups (prozacbear, 2010). He announces that this second version breaks the cardinal rules of magic, and indeed it does. As stated previously, magicians are not supposed to repeat a trick or reveal the endgame, for fear of giving away the method (Fitzkee, 1945/2009; Nelms, 1969/2000). Not to mention the audacity of using clear cups! Winn (2000) posits that Penn and Teller only perform tricks in order to debunk them, which he calls the "payoff" of the whole process. However, Penn and Teller's goal may be a little more complicated than Winn suggests-during the second half of the trick, the magicians are moving 
so quickly that it is difficult to follow their motions even as Penn narrates what is occurring (Lehrer, 2009).

These two tricks illustrate one of Penn and Teller's main critiques of the magic community: Too frequently, they claim, magicians underestimate the intelligence of their audience (Alesia, 1994, p. 3). Teller asserts that he and Penn are the only performers who are "willing to acknowledge...that the culture is savvy to magic" (Cohen, 1994, p. H1), and he cautions aspiring conjurors: "You're not performing for benighted savages. Treat them accordingly" (in Pelley, 2011, para. 3). Penn and Teller characterize their style as "intellectual" (Cohen, 1994). They want the audience to use their illusions as a launch pad for critical thinking; they want them "to think, not be fooled" (Jillette in Valania, 1992, para. 3). This is why they break down complex sleight of hand maneuvers and tantalize the audience's cerebral cortexes with transparent cups - to encourage analysis and skepticism in a public that too often accepts everything at face value. Treating the audience "like intelligent adults" (Lehrer, 2009) has other benefits as well-it means that Penn and Teller are less likely to offend spectators since they do not begin with the assumption that the audience must be stupid (Andrew, 2010). Of course, by revealing their tricks, Penn and Teller are also building tension and release to mask their larger trick. These are "sucker gags," or tricks with an "exposure with a sting in the tail, leaving the audience more puzzled than ever" (Hay, 1972, p. 8). According to Hay (1972), the "central secret of conjuring is a manipulation of interest" (p. 2). Since Penn and Teller let the audience believe they are "in" on the trick, the magician duo actually divert the spectators from another ruse.

\section{PARODY BORN OF INTERTEXTUALITY: SHREDDING A RABBIT AND DROWNING TELLER}

Curtis (2006) observes that magic acts are "ripe for deconstruction" (para. 3). P\&T "pepper their performances with irony," playing on magical tropes and archetypes in order to entertain the audience and to force them to re-examine the way magic functions in modern society (eHow Contributor, 2012, para. 1). In one trick, Penn sits off to the side while Teller correctly identifies a spectator's card-after putting the entire deck through a chipper-shredder (MavisRileyJunior, 2007b). Then, he produces a rabbit from his top hat, secretes it within his jacket, and pretends to accidentally drop the bunny into the whirring blades of the machine. "Blood" and "fur" shoot out the slot, Teller proceeds to look sheepish, and the trick is over. This trick intertextually references all of the previous tricks that have involved the disappearance and reappearance of cards and rabbits. However, it parodies/deconstructs those tricks by "destroying" the artifacts involved, without bringing them back (indeed, the trick literally deconstructs the poor rabbit). To fulfill the comedic aspect of parody, this routine makes use of incongruity theory: Audience members at a magic show expect to see a rabbit pulled from a hat (which does happen), but not dumped into a chipper-shredder (which also happens). The 
subversion is undeniably humorous. As to the evaluative aspect of parody, perhaps Teller is making a (silent) statement about magicians who do not know how to properly handle animals within their act; perhaps he is critiquing the audience's expectation that all animals will make it through a magic show alive, restored from whatever trauma they may experience at the hands of the conjuror.

Penn and Teller perform a similarly macabre-and similarly intertextual-illusion involving a glass tank and gallons and gallons of water (MavisRileyJunior, 2011a). In this trick, Penn attempts to identify a spectator's card while Teller is submerged in a water tank, supposedly holding his breath. Penn "screws up" the trick, not finding the spectator's card on the first, second, or third try. Then, he riffles through the deck and throws cards everywhere in a frantic search, because Teller refuses to hand over the key to the water tank to save his own life unless Penn finds the right card. After five minutes, Penn gives up, reasoning that Teller must already be dead. He turns the tank around and sure enough, Teller is floating, seemingly lifeless. And, of course, the missing card (signed by the spectator) is tucked into the goggles of dear departed Teller. The audience might find it incongruous, and thus humorous, that Teller would be willing to die for his "art," and the audience would undoubtedly feel superior to the bumbling Penn, who cannot find the right card to save his (friend's) life.

This trick is also a satirical take on the life-or-death illusion. Penn is nonchalant about his friend's predicament for a long while, and although he panics for a short period of time, he does not ultimately seem that broken up about Teller's death. Penn compares this bit to the work of another famous illusionist:

When David Blaine does a water tank, all he's talking about is "I'm in the water, I' $m$ gonna drown, I might die, merhmrehmeh..." Our way of doing the water tank is, I'm gonna do a card trick, the card trick is what matters... and oh by the way, Teller's holding his breath during it. (bigthink, 2011)

Penn has contempt for magicians who overplay the "danger" associated with deathdefying magic tricks. Onstage, Teller has been "impaled, drowned, had an 18wheeler run over his face and been flattened by a washing machine" (Krewen, 1997, p. C8). But Penn usually inflicts these tortures with the unruffled air of someone who is making himself a sandwich. So, yes, P\&T often "choose gore...over mystery" (eHow Contributor, 2012, para. 3), but they also choose to ratchet that gore up to absurd levels, all the while reacting in a way that tells the audience everything is going to be okay. The two of them firmly hold that "magic's not worth dying for" (Pelley, 2011, para. 7). Neither Penn nor Teller has suffered more than a scratch while performing. Teller asserts that it would be immoral to perform truly dangerous tricks in front of a live audience, especially one including children, so the two make sure that all of their illusions are completely safe (Will, 1999, p. E-01). 
These tricks highlight another key component of Penn and Teller's rhetoric. They are tired of the lack of innovation in the magic community, and presumably hope that their parodic take on uninventive magicians will shame other performers into upping their game. Teller hates that most magicians perform variations of the same ten tricks ad nauseam (Kopf, 1997), and is notoriously unforgiving of unoriginality: "The theorists who spout that there's no such thing as a new trick-well, they are certainly talking about themselves" (in Maue, 2001, para. 5). Thus, in their own shows, P\&T either try to come up with entirely new tricks or to put a new and edgy spin on existing tricks (eHow Contributor, 2012). The onstage personas of Penn and Teller might seem like a couple of rebellious goofballs, members of the magic community agree that this duo is made up of two of the hardest workers in show business. An acquaintance praised the duo's work ethic: "I've never met two guys who will take a trick apart, rehash it, think about it, revamp it, spend a lot of money redoing it" (Ness, 2002). By intertexually parodying overdone magic acts (routines that are performed either too frequently or too dramatically), Penn and Teller are breathing new life into an old art form.

\section{AND THEN COMES THE REVEAL: "BLAST OFF” AND SAWING A WOMAN IN HALF}

In one of their more bitingly satirical tricks, "Blast Off," Penn and Teller take a wellknown illusion, splitting a person up into different boxes, and give it a twist (carlosalbertoteixeir, 2007). The first half of the trick is done straight-Teller climbs into a column of boxes painted to look like a rocket ship, and Penn moves these boxes all around the stage. Teller's head and limbs randomly poke out of the boxes, as if he has been sectioned off into three parts. A perfectly-timed rock song plays in conjunction with the trick: "Blast off! / First stage, you really blew my mind. / Next stage, I reached but could not find" (carlosalbertoteixeir, 2007). After the illusion is complete, and Teller is reassembled, Penn and Teller yet again break the rules of magic (similar to the cups and balls routine). Penn announces, "That's the way everyone else does it; this is the way we do it!" (carlosalbertoteixeir, 2007). He and Teller remove the rocket ship boxes and replace them with clear plexiglass boxes, and then they rip the cover off of the stage, revealing the hollow platform underneath their feet. Teller climbs into the boxes, and the song starts again, but with noticeably pointed lyrics: "Trap door! / First scam, you slip away from me. / Next scam, you're not where you should be..." (carlosalbertoteixeir, 2007). The audience watches as Teller slithers out of the boxes and underneath the stage floor, where he slides back and forth to poke his limbs and head out of the different sections. Because the floor and boxes are clear, spectators can see that Teller is not truly disassembled or reassembled - he is just in the right place at the right time.

In another jab at the secrets of the magical community, Penn and Teller perform an amusing take on a quintessential illusion: sawing a woman in half (waplet, 2009). Penn and Teller bring out Georgie, a showgirl, and help her into a box on top of a 
table. Then, they lower a buzz saw through the box, and slide metal plates into the gash to assure the audience that Georgie has been bifurcated. Penn announces that most magicians hurry through the rest of the routine so the audience does not discern the method. He explains that when a person shifts from vertical to horizontal, it is difficult to tell if their height changes. Then Teller removes the front of the table, and we see that the showgirl's rear is dipped down below the reach of the blade, shortening her by a few inches and providing the desired illusion. But the trick is not over yet. Penn and Teller fiddle with the blade, and saw through Georgie's hips and hindquarters! Blood flies everywhere and Georgie screams. Penn and Teller pull the sections apart, and guts are hanging from the mangled midsection. As the two magicians stammer, a restored Georgie walks out onstage. Penn explains that this trick is a double subversion: "Not only do we do a different trick, but we also give away how everyone else does it" (waplet, 2009). Historically, sawing a woman in half is very popular (Mangan, 2007). Penn and Teller's use and abuse of the illusion is just one more indication of their magical knowledge. As a parody, this trick takes advantage of the humor inherent in superiority: the audience can feel superior to poor Georgie, who gets caught on the bad end of the blade; to all those lesser magicians, whose simplistic trickery has been revealed; and even to Penn and Teller, who "mess up" the routine by halving Georgie. Of course, once Georgie reappears onstage, it is Penn and Teller who are superior-but they do not lord it over their audience, and thus do not alienate any of the spectators. In terms of parodic critique, this act can be seen as commentary on smug magicians that do not take the time to update their tricks.

Some magicians do not approve of Penn and Teller's tendency to reveal secrets. The cups and balls routine, in particular, received a great deal of backlash (in Maue, 2001, para. 41). Lehrer (2009) reports that the outrage about this trick was so severe that Penn and Teller were even threatened with physical violence. However, in his extensive discussion about the effect exposure has on magic, Andrew (2010) says that the magic community holds mixed opinions on the duo. Some magicians decry Penn and Teller for destroying the mysteries of magic. Others recognize that what Penn and Teller do will probably not end conjuring as we know it, and might even resuscitate what can be seen as a dying art form. Penn and Teller do not reveal the secrets of the magic community willy-nilly. In fact, Teller hates magical piracy: "I know how many years can go into one beautiful idea. And to see somebody simply lift that idea (invariably doing it badly or insincerely) makes my blood boil" (in Maue, 2001, para. 10). Instead, Penn and Teller almost always reveal the method behind either classic illusions (e.g. sawing woman in half) or illusions of their own design (e.g., one involving an electronic body double of Penn).

By revealing the trickery behind their tricks, Penn and Teller take the focus off of "magic" and direct the audience's appreciation elsewhere. Andrew (2010) suggests that Penn and Teller encourage the "appreciation of deception." He references the 
lyrics of "Blast off": "Ain't no mystery / It's just trickery" (carlosalbertoteixeir, 2007). Andrew (2010) claims that the above statement transcends "Blast off," and shows "what all magic is really about" (para. 7). Through their magic, Penn and Teller hope to reveal the real-life tension between "what is and what seems to be" (Lehrer, 2009, para. 2). They recognize that deception is an inescapable aspect of our lives, and hope to provide us with a way to recognize, resist, and even respect deception as an art form. Penn and Teller are outspoken skeptics and atheists (Gagnon, 2006); Penn refers to their act as "the most pro-science act in show business" (in Kopf, 1997, p. 7), and Valania (1992) claims that the act is "a response to the phony mysticism of New Age swamis and the pompous hocus-pocus routines of most magicians" (para. 1). In a twist on Lyotard's (1979/1984) original notion of scientific rationality as metanarrative, Penn and Teller laud scientific rationality over the mystical and metaphysical metanarrative of the magic community. But Teller does not want trick exposure to just be about deception:

Teller is anxious to expose the secret in the hope of allowing a fuller appreciation of that beauty. To allow you to be one of those people... who loves the beauty and also admires that he can't see the thread, even though [you] still look for it. (Abowitz, 2008, para. 48)

Revealing a trick does not have to be about mocking other magicians or pushing an agenda of skepticism. It can be about realizing that even though a person might know how they were fooled, "it makes the fooling not less but more impressive" (Curtis, 2006; Sorenson, 1994, para. 11). By this logic, there is no reason exposure of the method should mean a magic trick is ruined.

\section{THE PRESTIGE}

It is clear that Penn and Teller have added a fourth act to the basic pledge/turn/prestige format of most magic tricks. They almost always complete the first three stages. First, they make the pledge, showing the audience something "ordinary" (e.g., boxes painted with a rocketship), with the implication that something extraordinary will follow. Next, they execute the turn, following through on their implication and causing something unusual to occur (e.g. disassembling Teller). Finally, they perform the prestige, giving the audience the reveal that they are expecting (e.g. putting Teller back together). The illusion is complete, but the act does not stop. Penn and Teller proceed to show the audience exactly how the trick is done, revealing Teller's movements under the stage and between the boxes and entering into a phase that can be called, to borrow a term from dramatic theory, the dénouement. By overriding the magic community's metanarrative of secrecy, and revealing the methods behind their illusions, Penn and Teller are providing resolution for the audience. 
Tension is built up over the course of a magic trick-both dramatic tension and literal, stress-related tension. Not being able to release that tension by learning the method can leave audience members feeling "distracted, nonplussed, confounded, frustrated, thwarted and circumvented," especially if they feel challenged by the magician, and subsequently try and fail to figure out how the trick works (Fitzkee, $1945 / 2009$, p. 98). Spectators resent magicians who use their performances as an excuse to demonstrate that they are smarter and more talented than the audience, and who seem to keep secrets only so that they can feel special and important. When a magician lets spectators in on the secret, it gives those spectators an opportunity for cathartic release, which in turn leads to heightened satisfaction with the performance, as well as increased liking for the magician. Apart from simply being novel, Penn and Teller's unique approach may have made them popular because it does not shut audiences out, and it does not leave all the power in the hands of the two conjurors. Spectators are dazzled by Penn and Teller's skill and showmanship, and they are gratified by the pair's candidness. Through their parodic skewering of the pomposity and gratuitous secrecy of poor magicians, Penn and Teller demonstrate their respect for the audience, and the audience responds in a parallel fashion, with respect for Penn and Teller.

\section{AFTER THE PRESTIGE}

Penn and Teller are undeniably successful, and for years, they have been shaking up the magic community and providing an alternative to traditional conjuring. However, by engaging in parody, Penn and Teller are working within the discourse established by traditional conjurors. Phiddian (1997) explains that parody occurs within a text, without trying to "break out on its own into the zones of pure representation or originality" (p. 684). Parody has limited range; as a parasitic mode of expression, it is constrained by the text off of which it feeds (Druick, 2009). Thus, if parody strays too far from the subject matter it mocks, it is no longer a critique of that subject matter-it is merely faint mimicry. In order for a parody to be truly effective, it must contain clear references to the style it is attempting to imitate. As Sorenson (1994) states, "Because of their style, a Penn \& Teller show is unlike any other magic act. And, also because of their style, a Penn \& Teller show is classic magic" (para. 9). Even though Penn and Teller take magic performances to the next logical step, revealing the secret behind the trick they just performed, they are still operating within the discourse of performance magic. Gray (2005) describes the process in terms of genre: "parodic texts often invoke the correct generic grammar but turn on it and externalize it" (p. 227). In their act, Penn and Teller invoke the generic grammar of traditional conjuring. They are still performing on a stage, in front of an audience, with magical apparatuses, and, ultimately, their goal is the same as that of traditional magicians: they aim to entertain the audience. Penn and Teller style themselves as the "nemesis of magic" (Ness, 2002), but their anti-magic rhetoric is compromised by the fact that they have two opposing endgames. Hutcheon (1989) explains the two-mindedness of parody, stating that its goals are to 
"challenge those discourses and yet to milk them for all they are worth" (p. 16). Penn and Teller have been milking for years, using traditional stage magic as a template for everything they do. The duo wants to challenge the metanarrative of the magic community, but without the magic community providing a launch pad for their work, Penn and Teller would cease to be relevant.

As this analysis reveals, Penn and Teller are even more split-minded when it comes to the goal of conjuring. They want to use magic to highlight the deception of traditional magicians and increase skepticism in their audiences, sure-but they also want to amaze their audiences with airtight illusions like their version of sawing a woman in half. This is presumably why they only reveal the technique behind some of their tricks: Penn and Teller are not in any way committed to destroying magic as an art form. Yes, Penn and Teller are skeptics. But that does not mean they do not appreciate the craft to which each has dedicated decades of his life. Each of them has heroes in the magic community (Maue, 2000; Maue, 2001), and judging from their interviews, they seem to take pride in their illusions, especially those which professional magicians cannot figure out, such as their double bullet-catch illusion (Will, 1999). It is only substandard magicians that they truly resent, those that mimic old magic acts with no attempt at originality (Maue, 2001), and those that are too full of themselves to put on a good show, who strut around acting like "gods" (Kopf, 1997). So perhaps parody is the most appropriate performance choice for the duo. After all, parody simultaneously subverts and legitimizes genres (Hutcheon, 2002)it subverts by providing constructive criticism and new directions for the genre, and it legitimizes because there is no reason to parody something pointless. Parodying magic allows Penn and Teller to ridicule and reject certain parts of the genre, while (perhaps even secretly) embracing other parts.

It turns out that like their version of sawing a woman in half, Penn and Teller are themselves a double subversion. They want to be seen as anti-magicians, skeptics of everything the magic community has to offer. But I suspect that they also want to be seen as magicians, purveyors of an art form that has been around for thousands of years. Otherwise, why would the duo reveal certain secrets to their audiences, and keep other secrets to themselves? Teller (2007) himself has stated that he and Penn perform certain illusions to demonstrate how "simultaneously fascinating and disappointing secrets are" (pp. 217-218). Phiddian (1997) says that parody is "much more complicit with what it deconstructs than the blank idea of criticism suggests" (p. 681), and Penn and Teller provide an excellent example of this ideal.

\section{REFERENCES}

Abowitz, R. (2008) 'A Man, a Ball, a Hoop, a Bench (and an Alleged Thread)...TELLER!' [online]. Las Vegas Weekly. Available at: 
"http://www.lasvegasweekly.com/news/2008/nov/20/man-ball-hoop-bench-andalleged-thread-teller/" [Accessed 20 March 2012].

Alesia, T. (1994) 'Tricks for Kicks: It's a Magic Show for People Who Hate Magic Shows'. Wisconsin State Journal, 10 November, p. 3.

Andrew. (2010) 'Dealing With Exposure (Part 9)' [online]. Ye Olde Magick Blogge. Available at: "http://sleightly.com/ blog/2010/03/21/dealing-with-exposure-part-9" [Accessed 21 March 2012].

Best, S. \& Kellner, D. (1991) Postmodern Theory: Critical Interrogations. New York: The Guilford Press.

Bevel, M. W. (2004). 'Mystery, Magic, and Myth: The Power of Narrative'. Journal of Philosophy and History of Education, 54, pp. 15-18.

bigthink. (2011) 'Penn and Teller's Water Tank Trick' [online]. Youtube. Available at: “http://www.youtube.com/ watch?v=v54nv_XAusg” [Accessed 20 March 2012].

Bleach, C. (2014, January 28). Tommy's Story. The Tommy Cooper Society. Available at: "http://www.thetommycoopersociety.org/tommys-story.aspx." [Accessed 13 June 2014].

Brown, J. (1987) 'Penn \& Teller: The Wonder of it All!' The Washington Post, 4 June, p. C3.

Burger, E. (2009a) ‘The Magical Experience'. In: E. Burger, \& R. E. Neale eds. Magic and Meaning (2nd ed.). Seattle: Hermetic Press.

Burger, E. (2009b) 'Stories of the Origin of Magic'. In: E. Burger, \& R. E. Neale eds. Magic and Meaning (2nd ed.). Seattle: Hermetic Press.

Burger, E., \& Neale, R. E. (2009) Magic and Meaning. Hermetic Press.

carlosalbertoteixeir. (2007) 'Penn \& Teller - Magician Duo Reveals Trick On Stage' [online]. Youtube. Available at: "http://www.you tube.com/watch?v=2H81A3bU68k" [Accessed 20 March 2012].

Cohen, A. (1994) 'Penn and Teller's Stock in Trade Still Magic for Thinkers'. Pittsburgh Post-Gazette, 19 June, p. H1. 
Curtis, B. (2006) ‘Penn Jillette Revealed!' [online]. Slate. Available at:

"http://www.slate.com/articles/news_and

_politics/the_middlebrow/2006/02/penn_jillette.html” [Accessed 20 March 2012].

Druick, Z. (2009) 'Dialogic Absurdity: TV News Parody as a Critique of Genre'.

Television E New Media, 10 (3), pp. 294-308.

http://dx.doi.org/10.1177/1527476409332057

eHow Contributor. (2012) 'How to Perform Magic Like Penn and Teller' [online]. eHow. Available at: "http://www.ehow.com/how_2155175_perform-magic-likepenn-teller.html" [Accessed 20 March 2012].

Fitzkee, D. (2009) Magic by Misdirection. Provo, UT: Magic Box Productions. (Original work published 1945).

Fitzkee, D. (2009) Showmanship for Magicians. Provo, UT: Magic Box Productions. (Original work published 1943).

Fitzkee, D. (2009) The Trick Brain. Provo, UT: Magic Box Productions. (Original work published 1944).

Gagnon, G. (2006) 'Faces of the New Atheism: The Illusionists' [online]. Wired. Available at: “http://www.wired.com/ wired/archive/14.11/faces2_pr.html” [Accessed 20 March 2012].

Gilbert-Walsh, J. (2007) 'Deconstruction as Narrative Interruption'. Interchange, 38 (4), pp. 317-333. http://dx.doi.org/10.1007/s10780-007-9034-z

Gloye, E. E. (1978) Theatrical Magic. New York: Magic, Inc.

Goetsch, C. C. (1980) 'Parody as Free Speech: The Replacement of the Fair Use Doctrine by First Amendment Protection'. Western New England Law Review, 3 (1), pp. 39-66.

Gray, J. (2005) 'Television Teaching: Parody, The Simpsons, and Media Literacy Education'. Critical Studies in Media Communication, 22 (3), pp. 223-238.

http://dx.doi.org/10.1080/07393180500201652

Hass, L. (2007) Transformations: Creating Magic Out of Tricks. Theory and Art of Magic Press.

Hay, H. (1972) The Amateur Magician's Handbook. New York: Signet. 
Hutcheon, L. (1989) 'Historiographic Metafiction: Parody and the Intertextuality of History'. In: P. O'Donnell \& R. C. Davis eds. Intertextuality and Contemporary American Fiction. Baltimore: Johns Hopkins.

Hutcheon, L. (2002) The Politics of Postmodernism. New York: Routledge.

Jameson, F. (1988) 'Postmodernism and Consumer Society'. In: A. E. Kaplan ed. Postmodernism and its Discontents: Theories, Practices. London: Verso.

Jilette, P. \& Teller. (n.d.) 'A Twisted History' [online]. Penn \& Teller. Available at: "http://www.pennandteller.com/03/ coolstuff/bio.html” [Accessed 20 March 2012].

Kopf, J. (1997) 'Magic Meets the Absurd, At the Corner of Penn \& Teller'. Intelligencer Journal, 31 October, p. 7.

Kreuz, R. J., \& Roberts, R. M. (1993) 'On Satire and Parody: The Importance of Being Ironic'. Metaphor and Symbolic Activity, 8 (2), pp. 97-109.

http://dx.doi.org/10.1207/s15327868ms0802_2

Krewen, N. (1997) 'Duo Still Alive and Tricking'. The Toronto Star, 2 November, p. C8.

Lamont, P., \& Wiseman, R. (1999) Magic in Theory: An Introduction to the Theoretical and Psychological Elements of Conjuring. Hertfordshire, England: University of Hertfordshire Press.

Lehrer, J. (2009) 'Magic and the Brain: Teller Reveals the Neuroscience of Illusion'. Wired Magazine. Available at:

"http://www.wired.com/science/discoveries/magazine/17-

05/ff_neuroscienceofmagic?currentPage=all” [Accessed 20 March 2012].

Loshin, J. (2007) 'Secrets Revealed: How Magicians Protect Intellectual Property Without Law' [online]. To be published in Law and Magic: A Collection of Essays. Available at: "http://faculty.winthrop.edu/kosterj/WRIT510/readings/ intellectualproperty\%26magic.pdf" [Accessed 20 March 2012].

Lyotard, F. (1984) The Postmodern Condition: A Report on Knowledge. G. Bennington \& B. Massumi trans. Minneapolis, MN: University of Minnesota Press. (Original work published 1979).

Mangan, M. (2007) Performing Dark Arts: A Cultural History of Conjuring. Chicago: Intellect Books. 
Maue, R. (2000) 'Cuwenay: Where Our Guests Discuss Their Inner Views' [online]. Voices. Available at: "http://www.deceptionsunlimited.com/vapenn.html" [Accessed 20 March 2012].

Maue, R. (2001) ‘Cuwenay: Where Our Guests Discuss Their Inner Views’ [online]. Voices. Available at: "http://www.deceptionsunlimited.com/vateller.html” [Accessed 20 March 2012].

MavisRileyJunior. (2007a) Penn and Teller with John Cleese [online]. Available at: "http://www.youtube.com/ watch?v=58xyjOFkpxk" [Accessed 20 March 2012].

MavisRileyJunior. (2007b) Penn and Teller Vanish a Rabbit [online]. Available at: "http://www.youtube.com/ watch?v=z6LH7towwkY\&feature=related" [Accessed 20 March 2012].

Meyer, J. C. (2000) 'Humor as a Double-Edged Sword: Four Functions of Humor in Communication'. Communication Theory, 10 (3), pp. 310-331.

http://dx.doi.org/10.1111/j.1468-2885.2000.tb00194.x

Nardi, P. M. (1984) 'Toward a Social Psychology of Entertainment Magic

(Conjuring)'. Symbolic Interaction, 7 (1), pp. 25-42.

http://dx.doi.org/10.1525/si.1984.7.1.25

Neale, Robert E. (2009a) “Early Conjuring Performances.” In E. Burger \& R. E. Neale eds. Magic and Meaning (2nd ed.). Seattle: Hermetic Press.

Neale, Robert E. (2009b) “Matinée Magic.” In E. Burger \& R. E. Neale eds. Magic and Meaning ( $2^{\text {nd }}$ ed.). Seattle: Hermetic Press.

Nelms, H. (2000) Magic and Showmanship: A Handbook for Conjurers. Mineola, NY:

Dover. (Original work published 1969).

Ness, M. T. (Producer). (2002) Grand Illusions: The Story of Magic [Motion picture]. United States of America: Paragon Productions.

Ott, B., \& Walter, C. (2000) 'Intertextuality: Interpretive Practice and Textual Strategy'. Critical Studies in Media Communication, 17 (4), pp. 429-446. http://dx.doi.org/10.1080/15295030009388412

Oxford English Dictionary. (2012). ‘Denouement' [online]. Available at:

"http://oxforddictionaries.com/definition/ denouement" [Accessed 3 April 2012].

Pelley, R. (2011) ‘Penn \& Teller Reveal the Secrets of TV Magic' [online]. The 
Guardian. Available at: "http://www. guardian.co.uk/culture/2011/jun/18/penn-andteller-secrets-of-tv-magic/print" [Accessed 21 March 2012].

Phiddian, R. (1997) 'Are Parody and Deconstruction Secretly the Same Thing?' New Literary History, 28 (4), pp. 673-696.

prozacbear. (2010) ‘Penn \& Teller Explain Ball \& Cups on Jonathan Ross 2010.07.09 (Part 2)’ [online]. Youtube. Available at:

"http://www.youtube.com/watch?v=8osRaFTtgHo\&feature=related" [Accessed 20 March 2012].

Robert-Houdin, J. E. (1877) The Secrets of Conjuring and Magic or How to Become a Wizard. L. Hoffmann, trans. London: George Routledge \& Sons.

Roper, D. (1986) The Comedy Magic Textbook. Norcross, GA: Snowflake.

Sankey, J. (2003) Beyond Secrets. Toronto: SankeyMagic.

Sharpe, S. H. (2003) Art and Magic. Seattle: The Miracle Factory.

Smith, S. A. (1993) 'Humor as Rhetoric and Cultural Argument'. Journal of American Culture, 16 (2), pp. 51-63. http://dxd.oi.org/10.1111/j.1542-734X.1993.00051.x

Sorenson, E. (1994) 'Magic for the Masses' [online]. Houston Press. Available at: "http://www.houstonpress.com/1994-04-07/culture/magic-for-the-masses/" [Accessed 30 March 2012].

Soteriou, H. (2010) 'Inside the Magic Circle of London' [online]. Londonist. Available at: "http://londonist.com/2010/ 05/inside_the_magic_circle_of_london.php" [Accessed 30 March 2012].

Teller. (2007) 'Teller: Entering Uncharted Terrain'. In P. McCabe ed. Scripting Magic. San Diego: Pete McCabe.

Thompson, C. J. (1992) 'Modern Truth and Postmodern Incredulity: A Hermeneutic Deconstruction of the Metanarrative of "Scientific Truth" in Marketing Research'. International Journal of Research in Marketing, 10, pp. 325-338.

Tu, J. I. (1997) 'The Magic of Penn \& Teller: Edgy, Ironic and Fun' [online]. The Seattle Times. Available at:

“http://community.seattletimes.nwsource.com/archive/?date=19971126\&slug=257455 8" [Accessed 20 March 2012]. 
Valania, J. (1992) 'Penn \& Teller Pull Barbs at Pretension from Magician's Hat' [online]. Morning Call. Available at: "http://articles.mcall.com/1992-1009/features/2893350_1_penn-teller-penn-jillette-david-copperfield" [Accessed 20 March 2012].

WastyinTahiti. (2009) 'Penn and Teller at Caesar's Palace' [online]. Youtube.

Retrieved from "http://www.youtube.com/ watch?v=FrY-KSc-5Lo\&feature=related" [Accessed 20 March 2012].

waplet. (2009) 'Penn and Teller @ Americas Got Talent S4E16 Season 4 Episode 16' [online]. Available at:

"http://www.youtube.com/watch?v=ytIUgB2jpos\&feature=related" [Accessed 20 March 2012].

Weber, K. (2003) Maximum Entertainment: Director's Notes for Magicians and Mentalists. Lake Success, NY: Ken Weber Productions.

Will, E. (1999) 'Gotcha: Penn \& Teller Keep Magic's Allure Alive and Full of Humor'. The Denver Post, 29 October, p. E-01.

Winn, S. (2000) 'Old Pros Show How it's Done; Penn \& Teller's Magic is in Showmanship'. The San Francisco Chronicle, 23 November, p. C1. 